Revista de

Contabilidade e

Organizações

www.rco.usp.br
DOI: http://dx.doi.org/10.11606/rco.v9i23.89956

Journal of

Accounting and

Organizations

\title{
Viability of using carbon credit futures in investment portfolios
}

\author{
Renato Marques da Silva ${ }^{\mathrm{a}}$; Flavia Zoboli Dalmacio ${ }^{\mathrm{b}}$ \\ ${ }^{a}$ Universidade de São Paulo \\ ${ }^{\text {b}}$ Universidade de São Paulo
}

\section{Article Info}

Histórico do Artigo

Recebido: 01 de fevereiro de 2014

Aceito: 02 de março de 2015

\section{Keywords:}

Carbon Credit,

Market Risk,

Viability

Investment portfolios

\begin{abstract}
With an odd pricing in the market, the Future Carbon Credit can act as mitigating risk when added to investment portfolios, ceasing to be simple positive socioenvironmental assets to bring real benefits to the strategy of the Portfolio. It can be noticed that, in fact, to introduce Carbon Credit Futures can reduce the value at risk of investment portfolios however it should be a concern to balance what is the optimal amount of futures contracts inserted in the portfolio in order to not take positions that would make the portfolio less efficient. It was used a theoretical portfolio of USD 1000.00, so that the participation of Carbon Credit Futures positions varied between $100 \%$ short position and $100 \%$ long position in the portfolio and, for each $1 \%$ change in participation of EUA futures, it was created a hypothetical portfolio, with its expected return, market risk and modified Sharpe ratio. This study found that there are financial advantages by introducing Future Carbon Credit in investment portfolios when it analyzes risk versus return of portfolios composed of these assets.
\end{abstract}

Copyright (C) 2015 FEA-RP/USP. Todos os direitos reservados

\section{INTRODUCTION}

With the growing concern about environmental issues, particularly those related to global warming and the greenhouse effect, during the Third United Nations Conference on Climate Change that occurred in 1997 in Kyoto, Japan, representatives from more than 160 countries signed the Kyoto Protocol.

The main objective of the protocol was to reduce the emission of gases that contribute to the greenhouse effect and to establish specific goals, which developed countries ${ }^{1}$ promised to reduce ${ }^{2}$ by $5.2 \%$ compared to 1990 levels, emissions of Greenhouse Gases (GHG) emissions between the years 2008 and 2012. As for the developing countries, there was no mandatory reduction target established mainly by the argument that, historically, they were not responsible for a significant portion of the gases already in the atmosphere.

The Government of the signatory countries then set out specific targets for the companies located in their countries in order to fulfill the promised reduction in the Protocol. However, this commitment could stifle the economy of these countries because they already had a productive structure based on more significant environmental impact technologies and changing it would require time. To aim a substantial growth of the economy and to reduce emissions of GHGs at the same time would be a virtually impossible task for any country. Therefore, it was established the possibility that these reductions Carbon could be traded between nations through the Flexibility Mechanism.

These emission reductions can be traded in the spot market or futures market, through its derivative, the Carbon Credit Futures, in order to protect companies that intend use them in the future against the price variation of this asset. Even with different opinions in the literature about the characterization of this type of asset, some 
authors, such as Giovanini (2010), understand the Carbon Credits as environmental commodities and, indeed, their understanding and trading in the financial market occurs similarly to the other commodities.

There are several types of Carbon Credit Certificates available in stock market and are used in different scenarios, depending on the need of the company that wants to use it. Besides the regulated use (or compulsory) for companies that need to reach their reduction targets of the Kyoto Protocol, there is also the voluntary use where companies who want to "reduce" (or compensate for) their carbon emissions voluntarily purchase these contracts.

According to Bennetti (2010), carbon credits can be likened to a financial instrument because they are intangible assets that are traded on the market like stocks and bonds. Credits traded on the spot market are considered commodities, whereas credits traded on the futures market are considered financial instruments.

This market is taking great proportions in recent years, reaching a turnover of U.S. \$ 176 billion in 2011, according to Kossoy and Guigon (2012), and Brazil has an important role in providing one of these types of products, accounting for about $8 \%$ of total world production of Certified Emission Reduction (CERs) and negotiating such type of reduction contract makes possible Brazilian projects that reduce GHG emissions.

Even with a large emitter of carbon credits market in the country, trading in the secondary market for such papers is practically null in Brazil, in other words, one performed by players who have no intention or need to use the contract in the future and negotiate mainly to profit by buying and reselling, winning the variation of asset prices, hardly exists in Brazil. This type of business is restricted to a specific platform for operations of BM\&F which operates only in the spot market. So the speculative market niche for this type of asset remains largely intact in the country.

The Green Bag of Rio de Janeiro (BVRio), which came into operation in 2012, are trading futures contracts Carbon Credit, which is expected to increase the liquidity of CER contracts in the country and start taking advantage of this niche market.

The investor that includes Carbon Credits in portfolios normally expects to use their environmental characteristic as a mean of marketing promote the portfolio. But there is no evidence to show how these contracts affect the portfolios and the impact within risk and return by including Futures Contracts of Carbon Credit on investment portfolios. Bennetti (2010) says an owner of emissions credits certainly has an expectation of return: The credits can be sold on the market for money; and the owner of an emissions credit accepts the risk that the market for credits will decline and credits will lose their value.

Besides, Seth and Kasius (2015) stated that several factors have stimulated the interest of few investors interested in climate change, among them the risk mitigation opportunities. According these authors, some investors have been reviewing ways to mitigate their risk exposure to high-carbon sectors and companies and, in Europe, insurance companies have recognized that the time horizon for projected climate change effects is not so dissimilar from the time horizons incorporated into the actuarial calculations of the industry.

This research seeks to demonstrate the impact of the use of futures Carbon Credit Future Contracts has on investment portfolios as the Market Risk and Expected Return, helping portfolio managers in the decision to take positions in the asset. Therefore we define our main question: there are financial benefits to include Future Carbon Credits in investment portfolios?

The paper is structured as follows: introduction; theoretical framework in which we discuss the major issues related to carbon credits; methodology, describing the means to achieve the objectives; presentation and analysis of results; and conclusions.

\section{THEORETICAL FRAMEWORK}

Through the Flexibility Mechanism, the agreements of the Kyoto Protocol opened space for undeveloped countries also join the scheme even that they did not committed to reduce their emissions of Greenhouse Gases (GHGs). It was also possible that companies from developed countries that reduces above their emissions quotas, could sell the reductions to companies that failed to achieve their goals.

The Flexibility Mechanism therefore has two major forms that relate to this study: the Clean Development Mechanism (CDM), which includes developing countries in the trade scheme, and Emissions Trading (ET), aimed reductions surpluses commerce between developed countries.

The CDM allows certification of emission reduction projects in developing countries and the subsequent sale of certified emission reductions, to be used by developed countries as a supplementary way for countries to meet their goals. This mechanism 
should result in additional emission reductions to those that would occur without the project, ensuring real, measurable and long-term climate change mitigation benefits. (Juras, 2007, p.4)

As for the functioning of the ET, when an industry in a country that has committed to reduce their emissions reduces beyond its goals, it receives a certificate authorizing the emission of polluting gases in the proportion of that surplus. This industry can, in turn, sell that license to another industry that failed to achieve its goal.

The sale of these types of license between different countries are given through international agreements, where countries form blocks of Carbon Credits transaction. The largest is the European Union Emissions Trading System (EU ETS), which are included 31 countries that transact through the EU ETS among themselves and accept, in controlled proportions, Papers from the CDM countries that do not make the block.

\subsubsection{The Market for Carbon Credits}

To be issued with a Carbon Credit from a CDM project, the amounts of CO2 and other gases saved or sequestered from the atmosphere by the project are measured and converted into carbon reduction called Certified Emission Reductions (CER) contracts.

Aiming reliability and, in turn, liquidity this paper, it must be certified by a Designated National Authority (DNA), which is in turn overseen by the international body Clean Development Mechanism Executive Board (CDM Executive Board). In Brazil, the DNA is the Interministerial Commission on Global Climate Change. The same happens in the ET: for the industry that reduces its emissions above the minimum established, certified carbon credits are generated in the same proportion to its surplus. This type of certificate, when coming from a country within the EU ETS scheme, is called Europe Union Allowance (EUA).

Both certificates are equivalent, each tonne of carbon or other gases causing the greenhouse effect, weighted by the importance of their reductions, such as methane gas that each ton is equivalent to 23 CERs (Senate Journal, 2007) or 23 EUAs. This is because methane is approximately 23 times more important in the formation of the greenhouse. Although both certificates are equivalent in terms of reducing emissions, CERs are less attractive assets in the market. This is because the industries that are part of the EU ETS scheme can use at most 13.4\% of CERs in mitigating their emissions in carbon credits (Bataller et al, 2010). Being the remaining percentage only eligible by contracts of EUA type.

What happens is that by not participating in the same scheme of emission credits, the EU ETS is unaware of the method of calculation and certification of CERs issued. But this measure can also be seen as a way of pressuring the non-signature countries, even those not developed, to accept the goals of the Kyoto Protocol. Currently, countries like China, Russia, Brazil and India are major emitters of GHGs, but do not have reduction obligations.

Similarly, the EU ETS had established that CERs from CDM projects that started after December 2012 will not be accepted within the European scheme. There was some hope on the part of the undeveloped countries, which did not occur in that undeveloped Climate Change Conference in Doha in November 2012 that date would be postponed. Thus, as of December 2012, only the roles of CERs generated by projects prior to be accepted by the EU ETS.

The origin of a project that results in tradable carbon credits is extremely diverse and can be derived from various sources. For example, a Small Hydropower Centre $(\mathrm{PCH})$, which produces clean electricity, i.e. without emitting GHGs as other energy sources emit and therefore also generates about 25,600 CERs per year (Artigiani, 2011), a hectare eucalyptus forest absorbs per year, equivalent to 12,000 CERs (Jornal do Meio Ambiente), a landfill that captures methane and turn it into electricity may be entitled to many tons of credits per year, for example.

According to the type of project that originates carbon credits, CERs are issued continuously for up to 30 years, as is the case of afforestation and reforestation (Giovanini, 2010). Thus, one can consider certificates of reducing greenhouse gases, both the USA and the CERs are potentially a byproduct produced by a wide range of markets, can be understood as an environmental commodity (Giovanini, 2010).

\subsubsection{Carbon Credit and Financial Market}

Industries who want to expand their production and therefore pollute more or that failed to achieve its 
goal of reducing its emissions in greenhouse gases can, through ET or CDM, buy Carbon Credits in the amount necessary for its goal is reached. That is, the company can buy the right to pollute in quantities proportional to the pollution that wishes to emit.

It works as if there is a transfer of financial resources from companies that pollute - or want to pollute more than they should for companies that have managed to reduce their greenhouse gas emissions beyond that established by the Kyoto Protocol.

Because there are fluctuations in the price of this type of contract, as with any commodity, the financial market has created CER and EUAs Futures Contracts, which meet the need that industries have to protect that price moves when they want to use them in the future. As mentioned previously, the reasons that CERs futures are less attractive are both by the old restrictions on their use in the compulsory EU ETS scheme and also by the decision of the European scheme no longer accept CERs produced from projects started after 2012, directly impacting on the price and liquidity active in this market.

\subsubsection{Risk of Futures Contracts for Carbon Credits and Pricing}

It is quite intuitive that the reasons that cause changes in market prices (returns) of financial assets (stocks, options, etc) and commodity futures diverge from each other. Mattos (2000) found evidences that this difference may become the use of agricultural commodities futures in portfolios advantageous. Similarly, this difference can also be applied to environmental commodities, however, some differences in the pricing of regular futures of commodities and environmental should be understood.

The so-called climate risks are a major limiter on the production of agricultural commodities. Problems such as seasonality, production losses due to climate problems, storage and distribution are the main sources of price volatility in this Market (Guimarães, 2005). The same reasoning can be applied to other types of commodities such as metals and petroleum, which verified the existence of risks in production and delivery of the physical product, there will be fluctuation in their market price due to this factor.

This factor is further intensified by the fact that the production of commodities are increasingly concentrated in a few producers (The Economist, 1999), both because oligopolies bring distortions in the pricing of a product and because of the increase of large risks being absorbed by few companies. It is easy to imagine the impact that a crisis in Venezuelan production chain would bring the price of oil, for example.

The large dispersion of the sources producing CERs and EUAs makes expected a decrease in the limiting factor in supply caused by problems in its supply chain, as would happen with common commodities and thus a supply of carbon credits homogeneous over time, without significant variations in price resulting from seasonality.

The Economic Theory of General Equilibrium conceptualizes two forces that are responsible for the pricing of an asset: its supply and its demand. For carbon credit contracts, however, the supply variable do not suffer from fluctuations from factors relating to production that are observed in other commodities, nor the concentration of production and therefore its price in the spot market is given uniquely in commodity market, which possibly makes this especially effective in mitigating asset market risk for an investment portfolio.

\subsubsection{Carbon Credits in Brazil}

Brazil has developed its energy production system mainly from renewable sources such as hydroelectric and extensive use of biofuels, which puts the country in a favorable situation for the issuance of carbon credits.

Large investments in the development of such technologies put the country in 2012 as the world's tenth largest investor in clean energy, investing around US\$ 8 billion (Journal of Science, 2012).

According to Santos Jr. (2006), Brazil is seen internationally as the country with the greatest potential for the sale of carbon credits and that indeed, one of the reasons is that the country's main energy source, the water, is clean and renewable. So performance in production of Carbon Contracts in Brazil is of great importance in the market. According Adeodato (2010), in 2010, Brazil ranked 3rd. position in production quantity of CERs, accounting for about $8 \%$ of total world production and, with the opening of the Rio Verde Stock Exchange, which negotiate carbon credit contracts, we expect a significant increase in trading volume of these papers and visibility of the country in that market. 


\subsubsection{Prospects for the Market Carbon Credits}

Originally, the Kyoto Protocol mentions that carbon reductions would be mandatory only until December 2012 for signatory countries. This meant that, after that date, the market for carbon credits could be reduced only to the voluntary market. Fortunately, in December 2011 at the Durban Conference, the signatory countries renewed the agreement until December 2017 with expectations for another renewal for 2020.

However, in late 2011 the EU ETS decided to not accept CERs issued by the CDM projects started after 2012. On its website, the European Commission made clear that “... projects registered before 2013 will be sufficient to meet the demand for CERs in accordance with current limits on imports". This will certainly imply a drastic price reduction of this type of role in the financial market.

At the last Conference in Durban, key countries to the future of the carbon market such as Brazil, Russia, India and China were placed on behalf of future generations to accept binding targets for reductions in greenhouse gas negotiations.

The expectation, even seemingly utopian, that one day all countries to commit binding emissions reductions will bring a strong warming in the carbon credit market, benefiting countries with great potential issuance of such contracts, as is Brazil. Brazil should also reevaluate its position for not having accepted yet mandatory reductions, since it holds such a potential on production that could be better exploited in any inclusion of the country in some of the reduction schemes (such as the EU ETS).

\subsection{Risk and Return of Portfolios}

\subsubsection{Portfolio Theory}

According to Markowitz (1952), an investor always expects him to maximize returns on the amount invested, ie, seeks to increase his expected return, without adding greater risks than willing to be taken by the investor. Also according to Markowitz (1952), in order to increase expected returns without increasing risks, diversification is necessary, building a portfolio of different assets whose prices do not vary together in the same direction and proportion.

Tosta de Sá (1999) notices that the coefficient covariance, which measures the joint variation between asset returns, when minimized, also minimizes the integrated portfolio risk:

The lower the covariance between the returns of the two securities, the lower the risk of the portfolio, and more, when the covariance is negative, the risk of the portfolio will be less than the weighted average risk of the individual securities that comprise it. This is the great secret of efficient diversification proposed by Markowitz. (SA, 1999, p. 70)

Correlation coefficient, similarly, shows how the two assets returns behave comparatively over time. The lower the correlation between them the less equally their returns behave. In the limit, a correlation of minus one, if established a shock of $+10 \%$ in value of an asset, at the same time there will be a clash of $-10 \%$ in value of the second asset. Thus, the more different assets in the portfolio are, the lower the correlation coefficient.

In his work, Mattos (2000) realized that there is often a low level of correlation between commodity futures and stocks and when commodity futures contracts are added in ideal proportion, et resulted in the modification of the risk-return of the portfolios, making them more attractive financially.

Obermayer (2009) showed in his work that the correlation between changes in the prices of carbon credit futures contracts and other financial assets are virtually negligible. This is probably due to the fact that the differentiated pricing of these futures contracts, as mentioned earlier.

As for the expected return, it is known that there was a depreciation in the market value of such contract, mainly motivated by the recent global economic crisis. However, as this devaluation can be seen in a generalized way in the market, and it should be analyzed what is the impact that the insertion of Futures Contracts Carbon Credits will bring the portfolio. What will be studied is the ideal proportion of assets (Carbon Credits futures versus Stocks) in which there is a reduction in market risk without deterioration of Expected Return Portfolio. 


\section{METHODOLOGY}

\subsection{Considered Assets}

The BM\&FBOVESPA index (IBOVESPA) represents approximately $85 \%$ of the total volume of transactions in the country and is an indicator widely used as a benchmark (benchmark) of several indexed portfolios. Although there are possibly more efficient portfolios than the theoretical portfolio measured by the IBOVESPA, Nakamura (2000) showed that it is reasonable to use as a benchmark BM\&FBOVESPA in the stock market, especially because of the impossibility to construct theoretical portfolios of all possible actions and choose a due to the large number of shares traded in the market. Thus, the IBOVESPA is assumed as an ideal portfolio of stocks.

Additionally, the American NASDAQ Index, the Brazilian Corporate Sustainability Index (ISE) and the Commodities Thompson Reuters / Jefferies CRB Index will be used in order to analyze the behavior of adding different amounts of carbon credits futures in other types of portfolios.

The choice of assets to represent Carbon Credit Futures was based on reasons mentioned above and the most liquid and with greater attractiveness in stock market are USA type and so that is why this contract is most relevant for this study. It is worth noting also that the prices of CERs and EUAs are highly correlated, above 0.9 (Kossoy and Guigon, 2012), ie, it can be assumed that the findings of EUAs may also apply to CERs.

USA futures are traded with maturities of every three months, December, March, June and September. Returns relating to the nearest maturity (first maturity) contract will be considered, as they have greater liquidity and are therefore closer to an efficient market.

\subsection{Collected data}

Closing prices of IBOVESPA, NASDAQ, ISE, Thompson Reuters/Jefferies CRB Commodities Index and first maturity contract of USA futures were extracted from a Bloomberg terminal and converted to US dollar currency. The period of collected data was from January 2, 2012 to June 24, 2013.

\subsection{Return Calculus}

As a common practice in finance, it is assumed that the logarithmic returns follow a normal distribution and can take values from $-\infty$ to $+\infty$. The alternative, the linear return, whose practice is not as widespread, has so insignificant difference as the results tend to zero and, in the case studied, the daily returns, this value tends to zero. Despite being a frequently discussed theme in literature, the assumption that asset returns follow normal model is widely used both in the financial market and the scientific literature. This is mainly because it is reasonably safe to use this assumption and calculations and results become more intuitive.

Thus, the returns to long positions of all assets considered are calculated by:

Where, $\mathrm{R}_{\mathrm{t}}=$ Asset return at $\mathrm{t}$ moment.

$$
R_{t}=\ln \left(\frac{P_{t}}{P_{t-1}}\right)
$$

$$
\begin{aligned}
& \mathrm{P}_{\mathrm{t}}=\text { Asset closing price at } \mathrm{t} \text { moment. } \\
& \mathrm{P}_{\mathrm{t}-1}=\text { Asset closing price at } \mathrm{t}+1 \text { moment. }
\end{aligned}
$$

Because futures contracts can also take short positions, the result of short positions will be exactly the opposite result value of the long position.

The return of the portfolio when combining one index and EUA Futures (EUAfut) is given by:

$$
R_{t}=R_{t}^{i} \times w^{i}+R_{t}^{f} \times w^{f}
$$

Where, $\mathrm{R}_{\mathrm{t}}^{\mathrm{i}}=$ Index return at $\mathrm{t}$ moment.

$\mathrm{w}^{\mathrm{i}}=$ Index weight on the portfolio.

$\mathrm{R}_{\mathrm{t}}^{\mathrm{f}}=$ Retorno do Contrato Futuro de primeiro vencimento no instante $\mathrm{t}$. 
$\mathrm{W}^{\mathrm{f}}=$ peso do Contrato Futuro de Crédito de Carbono na carteira.

As it can be assumed that future returns will follow the Historical Returns, Expected Returns for Index Futures Contracts are given by the average of the observed returns over the analyzed period, so that:

$$
\mathrm{E}(\mathrm{R})=\frac{\sum_{i=1}^{n} R_{t}^{i}}{n}
$$

Where, $\mathrm{E}(\mathrm{R})=$ " Expected Return.

$\mathrm{R}_{\mathrm{t}}^{\mathrm{i}}=$ Observed return at $\mathrm{t}$ moment.

$\mathrm{n}=$ number of days in the the period analyzed.

Analogously to (3):

$$
E\left(R_{t}^{c}\right)=\mathrm{E}\left(R_{t}^{i}\right) \times w^{i}+E\left(R_{t}^{f}\right) \times w^{f}
$$

Where, $\mathrm{w}_{\mathrm{f}}=$ Carbon Credit Futures weight in the portfolio

$$
\begin{aligned}
& E\left(R_{t}^{f}\right)=\text { Carbon Credit Futures Expected Return. } \\
& W_{i}=\text { index weight in the portfolio } \\
& E\left(R_{t}^{i}\right)=\text { Expected index return. } \\
& E\left(R_{f}^{c}\right)=\text { Expected portfolio return. }
\end{aligned}
$$

\subsection{Portfolio Risk}

The Value at Risk (VaR) is one of the most widely used statistical tools on the market to manage the market risk of positions taken by an investor. It is expressed by the financial value that, given a level of confidence, is the maximum expected loss for the portfolio in the set period of time. It is an intuitive value and can be understood by any portfolio manager.

For this study, a confidence level of $99 \%$ and one day time horizon, so has the VaR as the maximum dollar loss, with $99 \%$ confidence that the portfolio can suffer in a day.It is available in the literature mainly three models for calculating market risk: historic, parametric and Monte Carlo simulation, each taking advantages and disadvantages in their use.

The parametric model assumes that all risk factors inherent in the portfolio follow a parameterized distribution and requires the estimation of a covariance matrix, which for historical simulation is not necessary. On the other hand, the Monte Carlo model requires a very large computational effort, making its calculation very expensive.

It should also be taken into account the Historical Simulation method is relatively simple to obtain, is intuitive and robust. Besides, because it is based on observed real prices, it naturally incorporates nonlinearities of the results. Also, this model is indicated in the analysis of assets that has no studies on their probability distributions and have dubious liquidity.

\subsubsection{Historical Value at Risk}

This model uses historical returns of the assets in the portfolio, so that calculates the result of the portfolio held daily in the same manner in which it was presented in (3). Then, assuming that the portfolio composition remains constant over time it was observed, it is build a series of portfolio returns. Then, it is assumed that each result of the historical series of the result set of the portfolio corresponds to a scenario of change in risk factors, ie, each historical portfolio results correspond to a possible future outcome.

Thus, the result of historical VaR is given by using the formula:

$$
\mathrm{VaR}=E\left(R_{t}^{c}\right)-Q\left(R_{t}^{c}, 99 \%\right)
$$


Where, $\mathrm{VaR}=$ Value at Risk

$\mathrm{Q}\left(\mathrm{R}_{\mathrm{t}}^{\mathrm{c}}, 99 \%=\right.$ Return of the $99 \%$ quantile of the time series of portfolio returns.

$\mathrm{E}\left(\mathrm{R}_{\mathrm{t}}^{\mathrm{c}}\right)=$ Portfolio Expected Return

\subsection{Portfolio Risk-Return relation}

The Sharpe ratio (S) used to analyze the relationship between risk and return of an investment portfolio which aims to show the return received for each unit of risk of the portfolio and is one of the most widespread tools in the literature and in the financial market. With it, you can compare different investment portfolios and decide which has a better relationship between Risk and Return.

Some authors, however, noticed that the index developed by Sharpe had a failure for cases in which the expected portfolio return is negative. A simple modification of the original formula, developed by Israelsen (2005), solves this fault. Then it will be used in this work to the S modified formula:

$$
\text { modified } S=\frac{E\left(R_{c}\right)-E\left(R_{f}\right)}{\operatorname{Risco}^{\wedge}\left\{\frac{\left[E\left(R_{C}\right)-E\left(R_{f}\right)\right]}{\left[E\left(R_{C}\right)-E\left(R_{f}\right)\right] \mid}\right.}
$$

Where, $\mathrm{E}\left(\mathrm{R}_{\mathrm{c}}\right)=$ Portfolio expected return.

$\mathrm{E}\left(\mathrm{R}_{\mathrm{f}}\right)=$ Risk free expected return.

Risk $=$ Portfolio Risk $(\mathrm{VaR})$

A important variable to be set is the expected risk-free return. To portfolios consisted of EUA futures and Indexes traded in Brazil (BM\&FBOVESPA and ISE), the will be the value of the average CDI rate of the period analyzed, calculated on a daily basis multiplied by the hypothetical portfolio. The CDI rate was obtained in CETIP website. On the other hand, to portfolios that would be traded abroad composed by Indexes traded abroad (NASDAQ and Commodities), similarly, is used the Libor.

As explained earlier, to eliminate a possible bias due to the liquidity of the asset returns, EUA futures were divided into blocks framed by maturities so that the index returns in period $t$ will be calculated paired to the returns of the EUA futures contract first maturity in period t. Over this period, there is a total of 6 futures contracts analyzed, maturing in March/12, June/12, September/12, December/12, March/13 and June/13.

It was used a theoretical portfolio of USD 1000.00 and the data were calculated in MS-Excel, so that the participation of Carbon Credit Futures positions varied between 100\% short position and 100\% long position in the portfolio and, for each 1\% change in participation of EUA futures, it was created a hypothetical portfolio, with its expected return, market risk and modified Sharpe ratio. Thus, for every analyzed period (or maturity of futures contract) 2000 hypothetical portfolios are simulated, each containing $\mathrm{x} \%$ (variable) of EUA Futures Contracts and $(1-\mathrm{x}) \%$ of the considered index. Then a search was made for the portfolios that the percentage of each asset provided the minimum risk, maximum returns and optimal portfolio (maximum modified S), limited to:

The sum of assets in the portfolio to $100 \%$, the index does not take short positions, the EUA future may hold long or short positions, but limited between the quantities of $100 \%$ short to $100 \%$ long position of the portfolio.

It is also worth remembering that it is not considered the leverage strategy for positions in future carbon credit, ie, the positions long or short undertake the completeness of the portfolio position. As an example, a short position in $50 \%$ of future carbon credits compromise $50 \%$ of the capital invested.

\section{RESULTS}

After creating hypothetical portfolios for each period, for every index analyzed, tables were built explaining the portfolios that meet the main points (lower risk, higher return and higher S) for every contract. The tables in this section show in its first column the lower risk portfolios in the market and beside the reference values of obtained risk. Similarly, shows the highest expected returns and higher modified Sharpe Ratio. 


\subsection{BM\&FBOVESPA Index (IBOVESPA)}

For portfolios combined with the IBOVESPA and future EUA, Table 1 shows that for the first contract examined, with maturity on 26/03/2012, the lowest market risk in the amount of $\$ 22.52$ is reached with a short position $27.16 \%$ of future EUA. Comparatively, the risk obtained with a portfolio composed only of IBOVESPA is USD 34.26 .

It can be observed that with the exception of the period from 26/06 to 23/09/2012, in the analyzed period, the inclusion of moderate short positions (up 34\%) of future EUA reduces the market risk of portfolios when compared with the risk of portfolios composed only of IBOVESPA.

For maximum return, Table 1 shows that, for example, in the period from 27/03 to 25/06/2012, assuming $100 \%$ long position in future EUA resulted in a return of $\$ 1,197$, compared to a return of -5.246 if this position was $100 \%$ of IBOVESPA. It is observed that it is impossible to get an accurate standard position which will bring the best return, since in some periods the best return on portfolios is obtained only with carbon credits and in some periods only in portfolios with IBOVESPA.

Table 1: Portfolios that meet the main points analyzed composed by the IBOVESPA and future EUA. LP: long position. SP: short position

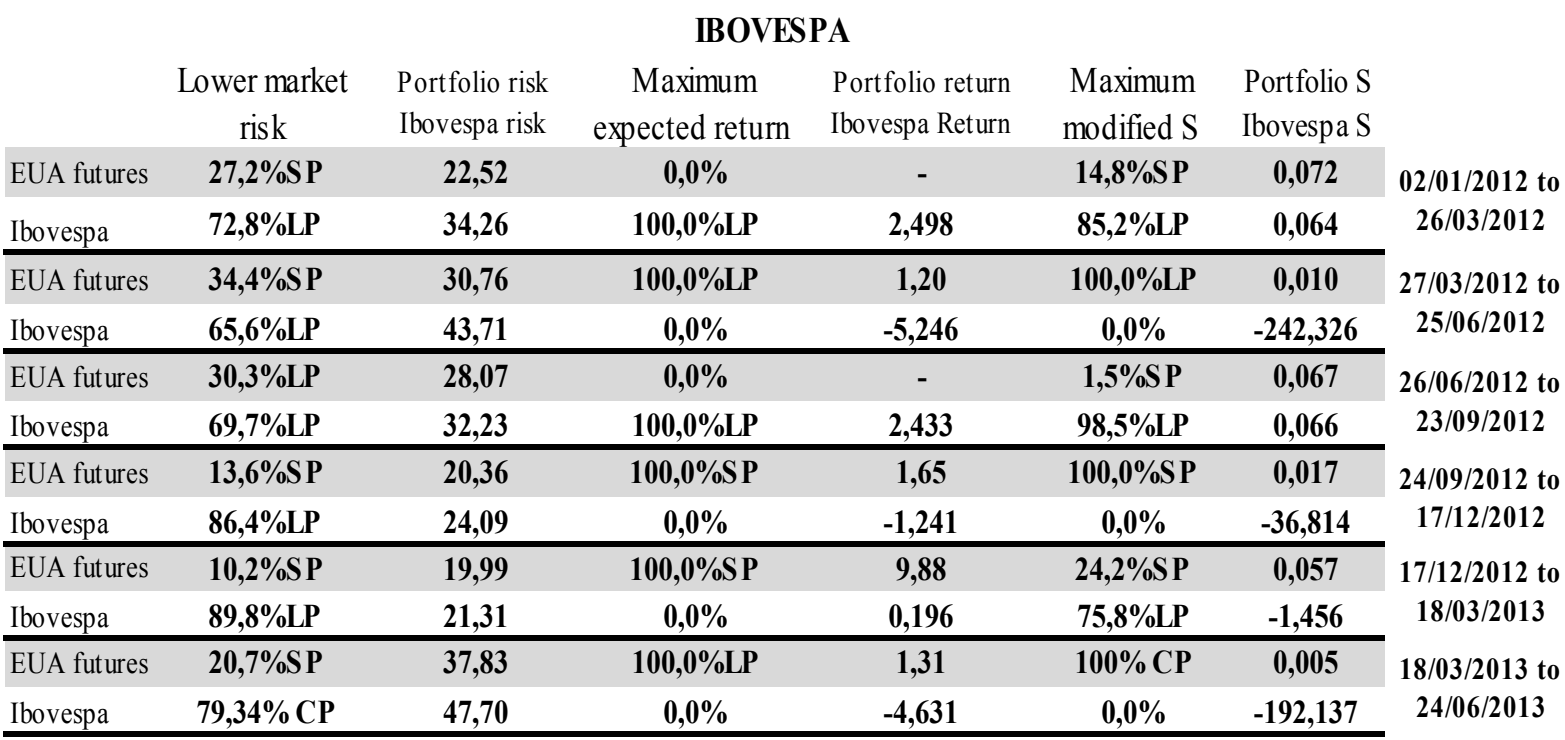

Analyzing the modified Sharpe ratio, it is observed that in the first analyzed period, from $02 / 01$ to 26/03/2012, the optimal portfolio (most modified S) is comprised of $14.8 \%$ short position in EUA future of first maturity bringing the $\mathrm{S}$ from 0.064 , with only a IBOVESPA, to 0.072 .

For the periods from 27/03 to 25/06/2012,24/09 to 17/12/2012 and 18/03 to 24/06/2013, the observed optimal portfolios were composed only by future EUA, which should be related to the particularly poor performance of the Brazilian market in periods. As for the other periods analyzed, it is seen that small insertions of short positions in Carbon Credits future create portfolios with better risk-return relationship.

\subsection{IBOVESPA, NASDAQ, ISE and CRB REUTERS compared results.}

Analyzing the variables searched in this work, the Minimum Risk, Maximum Return and maximum S compared between the Indexes cited, we can verify that the results remain constant in different types of portfolios. 


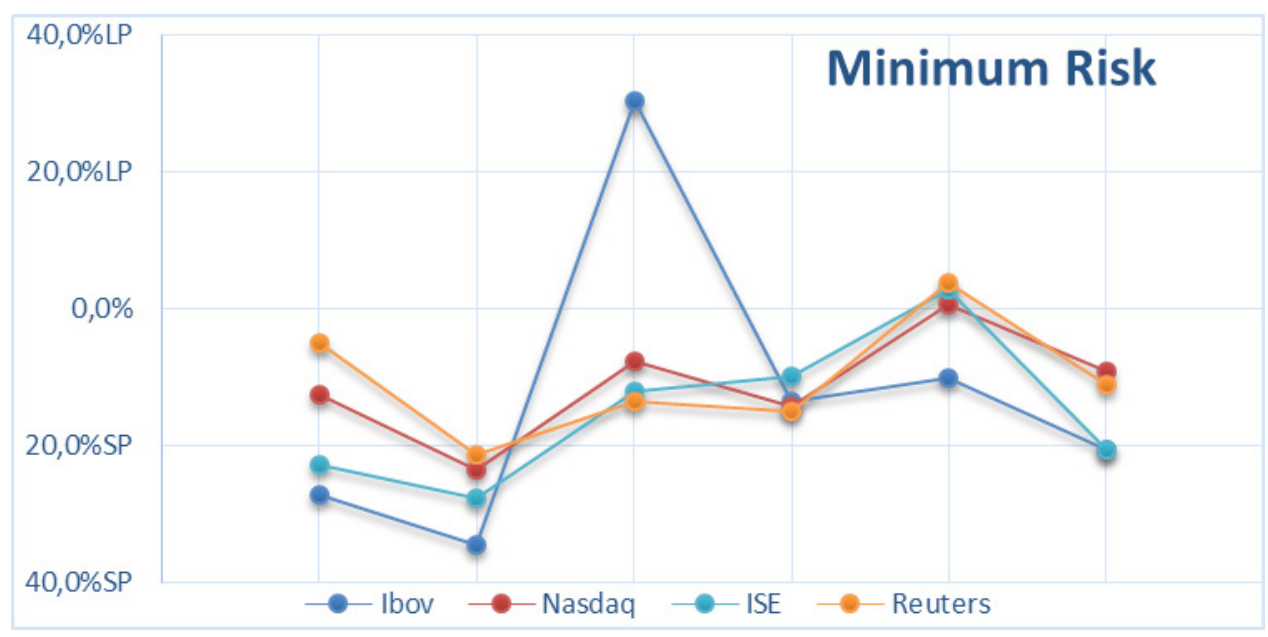

Figure 1: Positions in Carbon Credits that provide portfolios with the lowest market risk for the IBOVESPA, NASDAQ, ISE and CRB Reuters. LP: long position. SP: short position.

In a similar way to the IBOVESPA, it was observed that the combination of EUA future in portfolios represented by Indexes NASDAQ, ISE and CRB Reuters (Figure 1) also gets, in the analyzed period, reduction in market risk. In general, the amount of Carbon Credit futures which reduces the risk to a minimum varies mainly according to the analyzed period, but also according to the index analyzed.

As for the Maximum Expected Returns (Figure 2), as well as with the IBOVESPA, were quite volatile for the different periods analyzed in combination with other Indexes, sometimes belonging to the portfolio with $100 \%$ of the Index, and sometimes portfolios on $100 \%$ position of EUA future, it is difficult to determine which position will perform better.

It is worth noting that the positions provided the highest Expected Return had enough consistency among different index types within each period. The example we have for the first month, the best Expected return was achieved when no addition of carbon credits and yet, due in the second maturity analysis, the best return for all portfolios is achieved when all the investment is concentrated on EUA futures long position.

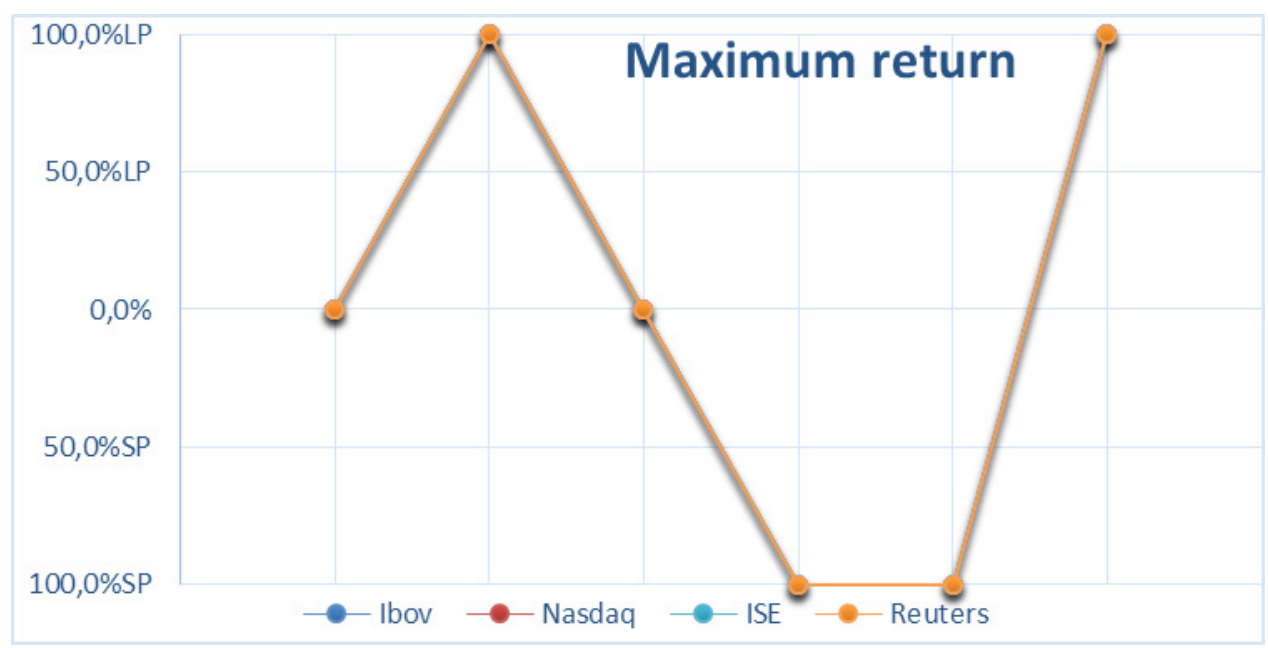

Figure 2: Positions on Carbon Credits that provide portfolios with Highest Expected return for IBOVESPA, NASDAQ, ISE and CRB Reuters. LP: long position. SP: short position.

The amount of future EUA to be added to the portfolio to maximize its Sharpe ratio (Figure 3) was quite 
variable between periods, making it difficult to determine the best-position to be taken on paper. However, it is noticed again that there was uniformity in results between the different types of portfolios, except the portfolio represented by IBOVESPA, whose addition of small amounts of long positions on EUA futures maximized Sharpe ratio.

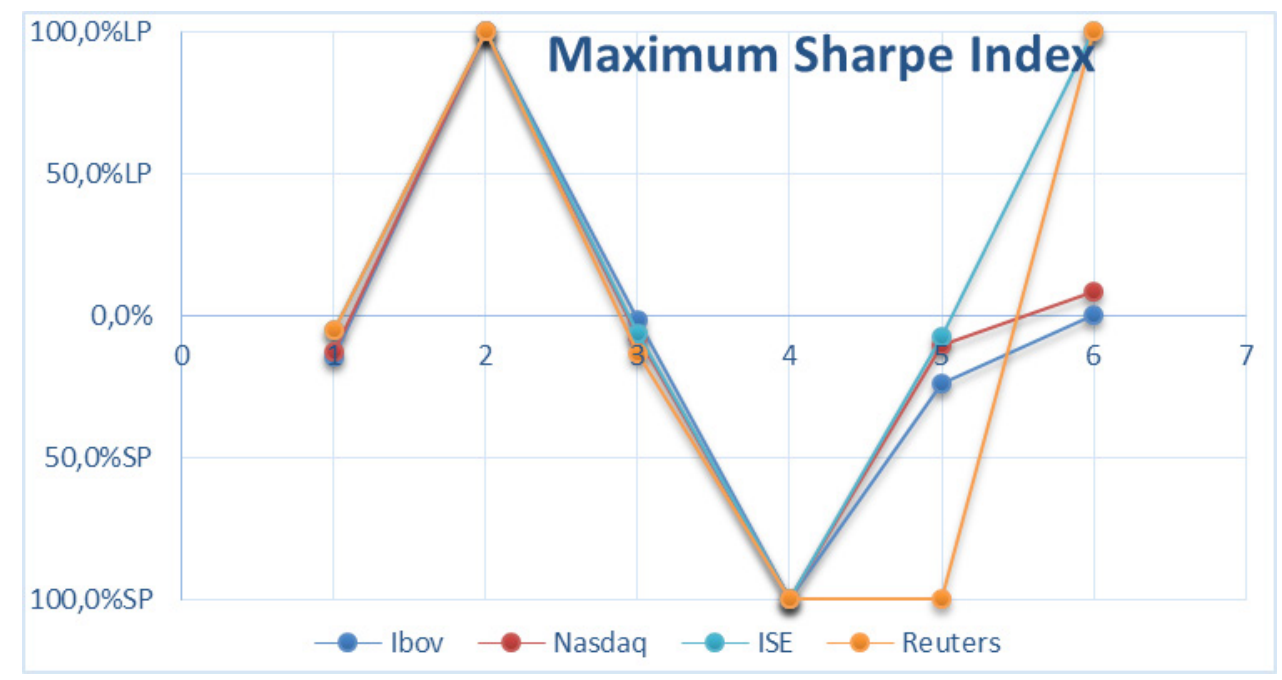

Figure 3: Positions on Carbon Credits that provide portfolios with the Highest Sharpe Ratio for the IBOVESPA, NASDAQ, ISE and CRB Reuters. LP: long position. SP: short position.

\section{CONCLUSION}

The addition of Carbon Credit Futures produced throughout the period analyzed portfolios with lower market risk when compared with portfolios composed only by stocks, whether they are represented by IBOVESPA, ISE or NASDAQ, and also the composite portfolio only commodities futures, represented by Thompson Reuters / Jefferies CRB.

The proportion of future carbon credits in the portfolio that minimizes the risk varied considerably over time, but it is noticed that there was a trend to small amounts added in a short position, on average $12.3 \%$, and that these values vary set for the different types of portfolios, showing that the effect observed by the introduction of carbon credits is more universally valid, because it includes both portfolios formed by stocks (IBOVESPA, ISE and NASDAQ) as formed by commodities (CRB).

Most of the analyzed period long series of negative returns for both indexes and for the future contracts were observed, since the Economical moment was of general crisis. It is difficult to analyze the results in relation to Expected return, showing the most favorable portfolios are composed in some periods by $100 \%$ of index and another periods, $100 \%$ in EUA futures.

By combining the analysis of Expected return and Market Risk through the modified Sharpe ratio, it is seen that throughout the analyzed period were found optimal portfolios that contemplated carbon credits futures in its composition.

It can be noticed that, in fact, to introduce Carbon Credit Futures can reduce the value at risk of investment portfolios however it should be a concern to balance what is the optimal amount of futures contracts inserted in the portfolio in order to not take positions that would make the portfolio less efficient.

Carbon Credit Futures demonstrated to have a great power to reduce market risk, but their use in investment portfolios does not have a significant market penetration. The reasons that lead managers of investment portfolios to reject such papers need to be further studied and tested for consistency, mainly because there is a great potential of this paper in the secondary market, mainly in Brazil. 


\section{REFERENCES}

[The] Economist. (1999). Commodities get big, available in http://www.economist.com/node/235005. Acessed October 10, 2012.

Adeodato, S. (2010). Mercado de Carbono deve superar frustração da COP, Valor, notícia available in http://www. mct.gov.br/upd_blob/0216/216634.pdf. Acessed October 23, 2012.

Artigiani, H. (2011). Crédito de Carbono como meio de Funding para empreendimentos de infraestrutura no Brasil - a validação de investimentos em geração de energia, ed. rev., USP, São Paulo.

Bataller, M.M et al. (2010). The EUA-sCER Spread: Compliance Strategies and Arbitrage in the European Carbon Market, Caisse des Dépôts.

Bennetti, Lisa (2010). Are tradable carbon emissions credits investments? Characterization and ramifications under international investment law. New York University Law Review. V. 85, p. 1581-1617. Available in http:// www.nyulawreview.org/sites/default/files/pdf/NYULawReview-85-5-Bennett.pdf. Acessed July 13, 2015.

Giovanini, D. et al. (2010). Análise do Mercado de Créditos de Carbono: Aplicação de projetos MDL no Brasil., V Encontro Nacional da Anppas, Florianópolis.

Guimarães, L.; Teixeira S. (2012). Gestão do Risco de Preços na Comercialização Agropecuária. Available in http://www.seplan.go.gov.br/sepin/pub/conj/conj5/10.htm. Accessed October 1th, 2012.

Israelsen, C. (2005). A refinement to the Sharpe Ratio and information Ratio, Journal of Asset Management.

Jornal do Senado. (2007). Como Funciona o Mecanismo de Desenvolvimento Limpo, available in http://www12. senado.gov.br/noticias/jornal/edicoes/2007/03/12/como-funciona-o-mecanismo-de-desenvolvimento-limpo. Acessed October 15, 2012.

Journal of Science. (2012). EUA reassumem a ponta do investimento em energia limpa. Available in http://www. jornaldaciencia.org.br/Detalhe.jsp?id=81980. Acessed October 24, 2012.

Juras, I. (2007). Mecanismo de Desenvolvimento Limpo: Fundamentos, Histórico e Estatística, Biblioteca Digital Câmara, Brasília, May.

Kossoy, A.; Guigon, P. (2012). State and trends of the Carbon Market 2012, The World Bank.

Markowitz, H. (1952). Portfolio selection. Journal of Finance, v. 7 p. 77-91.

Mattos, F. (2000). Utilização de contratos futuros agropecuários em carteiras de investimentos: uma análise de viabilidade. São Paulo.

Mcleod, W; Vuuren; G. (2004). Interpreting the Sharpe Ratio when excess return are negative. Investment Analysts Journal, n. 59.

Nakamura, W. T. (2001). Estudo Empírico sobre a eficiência da carteira teórica do índice Bovespa. Revista de Administração Mackenzie. Ano 1, n.1, p. 67-81.

Obermayer, J. (2009). An analysis of the fundamental price drivers of EU ETS carbon credits.

Questions and answers on use of international credits in the third trading phase of the EU ETS, 2011, available in http://ec.europa.eu/clima/policies/ets/linking/docs/q_a_20111114_en.pdf. Acessed November 27, 2012.

Santos Jr., M. F. (2006). O impacto dos créditos de carbono na atratividade econômica de Pequenas Centrais Hidrelétricas. Pará, 2006, 9p. - Espaço Energia, n. 5, October.

Seth, Camila; Kasius, Andrew. (2015). Investors' views on climate change. Climate Change and Development, p. 201-211, available in http://environment.yale.edu/publication-series/documents/downloads/o-u/Seth.pdf. Acessed July 14, 2015.

The World Bank. (2007). Growth and CO2 emissions: How different countries Fare? October. 